\title{
Preference Selection Index Method for Machine Selection in a Flexible Manufacturing Cell
}

\author{
Shaoyong $\operatorname{Jian}^{1}$, Shi Ying * \\ ${ }^{1}$ Department of Mathematics and Computer Sciences, Xinyu University, Xinyu,338004, China \\ * Department of fundamental courses, Wuhan Technology and Business University Wuhan, Hubei,430065,China
}

\begin{abstract}
The selection of a desirable machine is an important concern for the manufacturing firm. The selection process contains some critical selection attributes and the task of this process is to choose the desirable machine from a number of candidate machines. Then the machine selection problem is actually a multi-attribute decision making problem. This paper will develop a preference selection index method to solve the problem of machine selection in a flexible manufacturing cell. A case study is used to demonstrate that the proposed method is effective and feasible.
\end{abstract}

\section{Introduction}

Manufacturing companies worldwide are forced to undergo transformation processes in order to improve their ability to succeed with their products on extremely competitive international markets. In this perspective, an adequate selection of the appropriate machine tools if often crucial but very difficult to achieve [1]. The paper [1] developed the TOPSIS method for solving packaging machine selection problem under intuitionistic fuzzy (IF) environment. The paper [2] solved the machine tool selection problem using a $0-1$ integer programming combining with genetic algorithm. The paper [3] proposed the AHP approach to the material tool selection problem. The paper [4] used the fuzzy AHP method to solve the machine selection problem, in which the evaluation attribute values are expressed with triangular fuzzy numbers. The paper [5] put forward a novel 0-1 integer programming model for solving a problem of dynamic machine-tool selection and operation allocatio -n with part and tool movement policies in a flexible manufacturing system(FMS) environment. Flexible manufacturing cell (FMC) is a group of machines, working together to perform a set of functions on a particular part or product, with the added capability of being conveniently changeable to other parts or products [6]. Flexible manufacturing cells (FMCs) have received great attention in today's dynamic manufacturing environment. The evaluation attributes of machine selection in a FMC include many influence factors, such as purchasing cost, machine type, number of machines required, productivity, production output requirements, product quality, task and operating preference, interrelation among operating processes, type of control and accuracy of the machine, number of available AGVs, etc. [6,7]. Many authors studied the machine selection problems in a flexible manufacturing cell (FMC). The paper [8] developed the AHP method to the problem of machine tool selection. The paper [9] developed an expert system for manufacturing systems machine selection. The paper [10] and the paper [11] put forward a fuzzy goal-programming approach to solve the machine tool selection problem. The paper [12] proposed a fuzzy AHP method for evaluating machine tool alternatives. The paper [13] developed the digraph and matrix methods for the machine group selection in a FMC. The paper [14] suggested a decision support system based on fuzzy AHP and fuzzy TOPSIS for the selection of machining centre. This paper will develop preference selection index method to solve the problem of machine selection in a flexible manufacturing cell. The rest of this paper is organized as follows. In Section 2 , the MADM model for machine selection problem is firstly established, and then the new decision method is proposed. In Section 3, a machine selection in a flexible manufacturing cell example is given to demonstrate the 
feasibility and effectiveness of the new method. Finally, Section 4 gives the conclusion of this paper.

\section{Preference selection index (PSI) method}

Preference selection index (PSI) method is firstly proposed by Maniya and Bhatt in 2010, which is not necessary to assign relative importance between attributes, but overall preference value of attributes are calculated using concept of statistics [15]. This method is specifically effective when there is conflict in deciding the relative importance between attributes and that is the advantage of PSI method. Using overall preference value, PSI for each alternative is calculated and alternative with higher value of PSI is selected as the best alternative. The detail calculation steps of PSI method are given as follows [15]:

Step 1. Identify the goal. Find out all possible the candidate machines (alternatives), selection attributes and its measures for the given application.

Step 2. Establish the MADM decision matrix. The solving each MADM problem begins with constructing decision matrix. Let $X=\left\{x_{1}, x_{2}, \quad x_{m}\right\}$ be a set of alternative, $O=\left\{o_{1}, o_{2}, o_{n}\right\}$ be a set of decision attributes or criteria, $a_{i j}$ is the performance of alternative $x_{i}$ on the attribute $o_{j}$. Then the machine selection problem can be expressed with the decision matrix form $A=\left(a_{i j}\right)_{m \times n}$

Step 3. Normalize the decision matrix $A$ into normalization decision matrix $R=\left(r_{i i}\right)_{m \times n}$.

The process of transforming attributes value into a range of $[0,1]$ is called normalization and it is required in MADM methods to transform performance rating with different data measurement unit in a decision matrix into a compatible unit[15]. The normalization method adopted from the paper [16], and the formulas are given as follows: If the the $j$-attribute is benefit attribute, then $r_{i j}=a_{i j} / \max _{1 \leq i \leq m}\left\{a_{i j}\right\}$; If the $\mathrm{j}$-attribute is cost attribute attribute, then $r_{i j}=\min _{1 \leq i \leq m}\left\{a_{i j}\right\} / a_{i j}$.

Step 4. Compute preference variation value $\left(\mathrm{PV}_{j}\right)$, which is defined as: $P V_{j}=\sum_{i=1}^{m}\left(r_{i j}-\bar{r}_{j}\right)^{2}$, where $\bar{r}_{j}=\sum_{i=1}^{m} r_{i j} / m$ is the mean of normalized value of attribute $j$.

Step 5. Determine overall preference value $\left(\Psi_{j}\right)$ for each attribute. To get the overall preference value, it is required to find deviation $\left(\Phi_{j}\right)$ in preference value $\left(P V_{j}\right)$ and the deviation in preference value for each attribute is determined using the following equation: $\Phi_{j}=1-P V_{j}$, and overall preference value $\left(\Psi_{j}\right)$ is determined using following equation: $\Psi_{j}=\Phi_{j} / \sum_{j=1}^{n} \Phi_{j}$. The total overall preference value of all the attributes should beone, i.e. $\sum_{j=1}^{n} \Psi_{j}=1$.

Step 6. Calculate the PSI $\left(I_{i}\right)$, where $I_{i}=\sum_{j=1}^{n} r_{i j} \times \Psi_{j}$, for each alternative.

Step7. Rank all the alternatives according to the PSI. After calculation of the PSI $\left(I_{i}\right)$, alternatives are ranked according to descending or ascending order to facilitate the managerial interpretation of the results, i.e. an alternative is ranked/selected fi rst whose PSI $\left(I_{i}\right)$ is highest and an alternative is ranked/selected last whose PSI $\left(I_{i}\right)$ is the lowest and so on.

\section{Case Study}

This example is taken from the case study conducted by Wang et al. [7]. Wang et al. [7] had presented a real case of a FMC including two CNC milling machines, one $\mathrm{CNC}$ lathe and one robot for material handling. In this problem the factory manager had decided to purchase some machine facilities after sufficient discussion and complete evaluation. The two CNC milling machines, one $\mathrm{CNC}$ lathe and a robot are composed into a possible alternative for the FMC, that is, all are put together and considered as a machine group required for FMC. After putting different purchasing constraints on the total purchasing cost, and the specifications of milling machine, lathe machine, and the robot, suitable machines of FMC were composed into ten 
possible alternatives. Evaluation attributes areTotal purchasing cost (dollars) $\left(o_{1}\right)$, Total floor space $(\mathrm{m} 2)$ $\left(o_{2}\right)$, Total machine number $\left(o_{3}\right)$, Productivity* $(\mathrm{mm} / \mathrm{min})$ $\left(o_{4}\right)$. Here, the value of Productivity corresponds to the machine with the slowest feedrate in FMC.

Table 1. Decision matrix and normalized decision matrix for machine group selection in an FMC [7].

\begin{tabular}{ccccc}
\hline \multirow{2}{*}{ No. } & \multicolumn{4}{c}{ Evaluation attribute values } \\
\cline { 2 - 5 } & $o_{1}$ & $o_{2}$ & $o_{3}$ & $o_{4}$ \\
\hline 1 & 581818 & 54.49 & 3 & 5500 \\
\hline 2 & 595454 & 49.73 & 3 & 4500 \\
\hline 3 & 586060 & 51.24 & 3 & 5000 \\
\hline 4 & 522727 & 45.71 & 3 & 5800 \\
\hline 5 & 561818 & 52.66 & 3 & 5200 \\
\hline 6 & 543030 & 74.46 & 4 & 5600 \\
\hline 7 & 522727 & 75.42 & 4 & 5800 \\
\hline 8 & 486970 & 62.62 & 4 & 5600 \\
\hline 9 & 509394 & 65.87 & 4 & 6400 \\
\hline 10 & 513333 & 70.67 & 4 & 6000 \\
\hline
\end{tabular}

\begin{tabular}{ccccc}
\hline \multirow{2}{*}{ No. } & \multicolumn{4}{c}{ Evaluation attribute values } \\
\cline { 2 - 5 } & $o_{1}$ & $o_{2}$ & $o_{3}$ & $o_{4}$ \\
\hline 1 & 0.8370 & 0.8389 & 1.0000 & 0.8594 \\
\hline 2 & 0.8178 & 0.9192 & 1.0000 & 0.7031 \\
\hline 3 & 0.8309 & 0.8921 & 1.0000 & 0.7813 \\
\hline 4 & 0.9316 & 1.0000 & 1.0000 & 0.9063 \\
\hline 5 & 0.8668 & 0.8680 & 1.0000 & 0.8125 \\
\hline 6 & 0.8968 & 0.6139 & 0.7500 & 0.8750 \\
\hline 7 & 0.9316 & 0.6061 & 0.7500 & 0.9063 \\
\hline 8 & 1.0000 & 0.7300 & 0.7500 & 0.8750 \\
\hline 9 & 0.9560 & 0.6939 & 0.7500 & 1.0000 \\
\hline 10 & 0.9486 & 0.6468 & 0.7500 & 0.9375 \\
\hline
\end{tabular}

The specific calculation steps of the proposed method are given as follows:

Step 1. The normalized attribute values are reported in Table1;

Step 2. The vectors of preference variation value $\left(P V_{j}\right)$, deviation $\left(\Phi_{j}\right)$, and overall preference variation value $\left(\Psi_{j}\right)$ are respectively obtain as:

$$
\begin{aligned}
& P V=(0.0379,0.1967,0.1736,0.0701) ; \\
& \Phi=(0.9621,0.8033,0.8264,0.9299) ; \\
& \Psi=(0.2732,0.2281,0.2347,0.2640) .
\end{aligned}
$$

Step 3. The preference selection index $\left(I_{i}\right)$ are calculated as $I=(0.8816,0.8534,0.8714,0.9566$, $0.8840,0.7921,0.8080,0.8467,0.8595,0.8302)$. Then the ranking order is $4-5-1-3-9-2-8-7-10-6$, which is almost the same as the one obtained in paper [6] 4 - 5 - 1 - 3 - 2 - 9 - 8 - 10 - 7 - 6 . The desirable machine is the machine No. 4 .

\section{Conclusion}

For the machine selection problem, we first construct a decision matrix, and then develop a new decision making method named preference selection index method for solving it. This method is specifically effective when there is conflict in deciding the relative importance between attributes. Finally, a case study is use to demonstrate and validate the application of the proposed method. The proposed method can also extend to other application to robot selection, investment selection and project selection.

\section{References}

1 D. Aloini, R. Dulmin and V. Mininno. A peer IF-TOPSIS based decision support system for packaging machine selection. Expert Systems with Applications, Vol. 41 (2014), p. 2157-2165.

2 C. Moon, M. Lee, Y. Seo and Y. H. Lee. Integrated machine tool selection and operation sequencing with capacity and precedence constraints using genetic algorithm. Computers \& Industrial Engineering, Vol. 43 (2002) ,p. 605-621.

$3 \mathrm{M}$. Yurdakul. AHP as a strategic decision-making tool to justify machine tool selection. Journal of Materials Processing Technology, Vol. 146 (2004), p.365-376.

4 O. Durán and J. Aguilo. Computer-aided machine-tool selection based on a Fuzzy-AHP approach. Expert Systems with Applications, Vol. 34 (2008), p. 1787-1794.

5 M. H. M. A. Jahromi and R. T. Moghaddam. A novel 0-1 linear integer programming model for dynamic machine-tool selection and operation allocation in a flexible manufacturing system. Journal of Manufacturing Systems, Vol. 31 (2012), p.224-231.

6 R. V. Rao: Decision Making in Manufacturing Environment Using Graph Theory and Fuzzy Multiple Attribute Decision Making Methods. (Springer-Verlag, London 2013). 
7 T. Y. Wang, C. F. Shaw and Y. L. Chen. Machine selection in flexible manufacturing cell: a fuzzy multiple attribute decision making approach. Inter $\mathbf{J}$ Prod Res, Vol. 38 (2000), p. 2079-2097.

8 Z. Taha and S. Rostam. A hybrid fuzzy AHP-PROMETHEE decision support system for machine tool selection in flexible manufacturing cell. J Intell Manuf, Vol. 23 (2012) p. 2137-2149

9 H. Chtourou, W. Masmoudi and A. Maalej. An expert system for manufacturing systems machine selection. Expert Syst Appl, Vol. 28 (2005), p. 461-467

10 F. T. S. Chan and R. Swarnkar. Ant colony optimization approach to a fuzzy goal programming model for a machine tool selection and operation allocation problem in an FMS. Robot Comput Integr Manuf, Vol. 22 (2006), p. 353-362

11 F. T. S. Chan, R. Swarnkar and M. K. Tiwari. A fuzzy goal-programming model with an artificial immune system (AIS) approach for a machine tool selection and operation allocation problem in a flexible manufacturing system. Inter J Prod Res, Vol. 43 (2005), p. 4147-4163

12 Z. Ayag and R. G. Ozdemir. A fuzzy AHP approach to evaluating machine tool alternatives. J Intell Manuf, Vol. 17 (2006), p. 179-190

13 R. V. Rao. Machine group selection in a flexible manufacturing cell using digraph and matrix methods. Inter J Ind Syst Eng, Vol. 1 (2006), p.502-518

14 Y. Tansel and M.Yurdakul. Development of a decision support system for machining center selection. Expert Syst Appl, Vol. 36 (2009), p. $3505-3513$

15 K. Maniya and M. G. Bhatt. A selection of material using a novel type decision-making method: Preference selection index method, Materials and Design, Vol. 31 (2010), p.1785-1789 